\title{
Research on the Optimization of Students' Entrepreneurship Education under the Mode of University-enterprise Cooperation: Based on the Survey of Guangdong
}

\author{
Zhenhua Zhang ${ }^{1,2, *}$, Jiawen Shen ${ }^{2}$ and Bing Chen $^{3}$
}

\author{
${ }^{1}$ Laboratory of Language Engineering and Computing, Guangdong University of Foreign Studies, Guangzhou, \\ Guangdong 510006, China \\ ${ }^{2}$ School of Mathematics \& Statistics, Guangdong University of Foreign Studies, Guangzhou, Guangdong 510006, China \\ ${ }^{3}$ School of Economics \& Trade, Guangdong University of Foreign Studies, Guangzhou, Guangdong 510006, China \\ *Corresponding author. Email: zhangzhenhua@gdufs.edu.cn
}

\begin{abstract}
Entrepreneurship education is important for higher education, and is inseparable from university-enterprise cooperation. In order to fully realize the status of entrepreneurship education in China, we conducted a survey in 12 universities in Guangdong. The statistical analysis of 570 individuals shows that students participating in university-enterprise cooperation are satisfied with the mode of university-enterprise cooperation. However, there are some shortcomings: three-quarters of students have not participated in university-enterprise cooperation; the students participating in university-enterprise cooperation receive insufficient professional guidance; some aspects need to be improved and optimized. According to the deficiencies in entrepreneurship education, we propose five suggestions: Enhance the awareness of entrepreneurship by "theory + practice", establish an office for handling university-enterprise cooperation in university, establish a "universityenterprise crowdfunding platform", make good use of the Entrepreneurship Education Institute, and attract enterprises to participate in the training plan of entrepreneurial talent. The results are conductive to China's entrepreneurship education.
\end{abstract}

Keywords: Entrepreneurship education; innovation education; university-enterprise cooperation;

cooperation model; college students; higher education

\section{INTRODUCTION}

At the Summer Davos Forum in September 2014, Chinese Premier Li Keqiang officially issued a call for "mass entrepreneurship and innovation". At that time, he proposed a new wave of "mass entrepreneurship" and "grassroot entrepreneurship", forming a new trend of "innovation by all people" and "innovation by everyone". Since then, in accordance with the requirements of the State Council, the National Development and Reform Commission has taken the lead in establishing the coordination mechanism of the national "Innovation and Entrepreneurship" inter-ministerial liaison meeting. The departments of central government and local government have issued more than 300 policies and more than 10,000 encouragement policies related to "Innovation and Entrepreneurship", including a series of policy documents such as Guofa No. 32 (2015), Guofa No. 37 (2017), and Guofa No. 32 (2018). According to preliminary statistics, up to now, with the "Innovation and Entrepreneurship" era background and policy support, universities have become more and more important for cultivating entrepreneurs. Innovation and entrepreneurship have gradually penetrated campuses, and an upsurge of innovation and entrepreneurship education is setting off.

With the development of science and technology and the advent of the "Internet + " era, the relationship between innovation in various industries and information network technology has become increasingly close. The integration of traditional industries and the internet has promoted the popularization of new technology applications and continued to effectively improve the real economy. Innovation and productivity, the new normal of economic development relying on the internet has been or is taking shape in various fields. Under the new normal of high-tech innovation and economic development, innovation and entrepreneurship education reform in the field of higher education is imperative. University students, as the group with the most free time and the most creativity, have become the focus of national entrepreneurship, and the entrepreneurial education of universities has attracted more and more attention from the government.

At present, many scholars have carried out the research on the status quo of entrepreneurship education in university. 
According to CNKI (China Journal Data Set), in recent years, the research on the entrepreneurship of college students has reached a climax, with a total of 75,900 papers. The amount of all papers on university-enterprise cooperation is as high as 119,600 . Among them, the amount of papers on the entrepreneurship of college students is 7,846 , and vocational education and university education each account for half of the total papers.

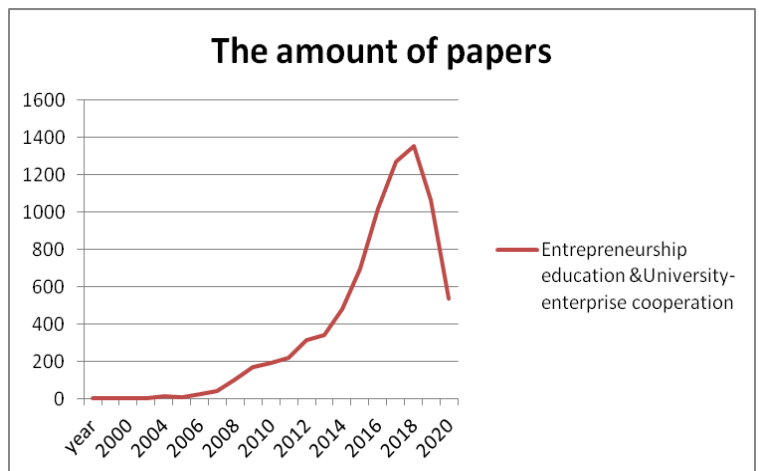

Figure 1. Amount of papers on entrepreneurship education \& university-enterprise cooperation in CNKI

In terms of entrepreneurship education for college students, Qiu [1], Huang and Guo [2] studied the curriculum system of entrepreneurship education, Gao [3] proposed countermeasures for the problems in entrepreneurship education. Tian [4], Chen [5], and Cheng [6] studied the construction of entrepreneurship community from the perspective of education ecology, and Shi and Zhao [7] focused on entrepreneurship education in vocational colleges. Gao [8] and Wang [9] studied the cultivation of entrepreneurial ability from multiple perspectives.

At present, there are many literatures on universityenterprise cooperation. For example, Dong [10] studied the Stanford University-Silicon Valley model. However, there are not many papers on entrepreneurship education among them. According to the literatures of CNKI, Yang [11] and Shen [12] studied the entrepreneurial education system of local universities from the perspective of universityenterprise cooperation. In recent years, the research on university-enterprise cooperation and entrepreneurship education is in the ascendant. For example, $\mathrm{Xu}$ et al. [13] took Nanjing University as an example to study the teaching reform of entrepreneurship practice. Dong et al. [14] explored the cultivation of entrepreneurial ability. And Cheng et al. [15] studied the training model of entrepreneurial talents. In short, the above literatures show that there have been some results in entrepreneurial education and university-enterprise cooperation. However, the current research on university-enterprise cooperation and entrepreneurship education still lacks data support. In view of this, we surveyed the arts, sciences, engineering, medicine, agriculture, and other majors in 12 universities in Guangdong Province, And carried out multiple types of onsite surveys. From the perspective of university-enterprise cooperation, we explored the existing status and problems of university entrepreneurship education, and seek suitable solutions.

The rest of the full paper will be divided into the following contents: The first part is the introduction of paper, the second part is the introduction of statistical survey and sampling methods, the third part is the statistical analysis of the survey data on the current status of universityenterprise cooperation, the fourth part is the conclusion and discussion of the survey, the fifth part is the countermeasure analysis, and the last is the conclusion.

\section{SURVEY AND DATA}

In order to gain an in-depth understanding of the current situation of college students' participation in universityenterprise cooperation models in Guangdong Province, as well as students' active awareness and realistic needs for university-enterprise cooperation, this paper designs corresponding questionnaires and conducts on-site investigations.

Sampling survey method is multi-stage sampling. We first classify all key universities in Guangdong Province, and choose 4 comprehensive universities, 2 technology and engineering universities, 2 medical universities, 1 language university, 1 normal university, 1 art university and 1 agricultural university as samples. In each university, we randomly draw some majors as samples, and conduct surveys in the same proportions for the four grades from freshman to senior.

In practice, we distributed questionnaires to students from 12 universities in Guangdong Province, including Sun Yatsen University, South China University of Technology, South China Normal University, Jinan University, Guangdong University of Technology, Guangdong University of Foreign Studies, Guangzhou University, Southern Medical University, Guangzhou University of Chinese Medicine, South China Agricultural University, Shenzhen University, Guangzhou Academy of Fine Arts. A total of 600 questionnaires were distributed and 600 questionnaires were returned. There are 570 valid questionnaires, with an effective rate of $95 \%$. Among all the students, 431 individuals have not participated in any form of university-enterprise cooperation activities, and 139 students have participated in some universityenterprise cooperation activities. The students who accepted this questionnaire survey came from freshman to senior students. 150 questionnaires were distributed for each grade, and there was only a slight difference in the number of valid questionnaires. Students' majors are widely distributed, covering 15 different majors, including Economics, Management, Mathematics, Engineering (Chemistry, Computer, Machinery, Transportation), Art, Agriculture, Literature, Linguistics, Law, Journalism, Clinical Medicine, and Chinese Medicine.

The main contents of the questionnaires include participation degree of students in the form of universityenterprise cooperation, students' evaluation of the form of university-enterprise cooperation, students' expectation on the form of university-enterprise cooperation, etc. 


\section{DATA ANALYSIS ON THE STATUS QUO OF UNIVERSITY-ENTERPRISE COOPERATION}

Interviews and surveys of teachers and students show that the current university-enterprise cooperation model mainly includes the following forms: training camps, cooperative projects, companies cooperating with universities as sponsors of competitions, and companies entering classrooms.

\subsection{The Degree of Participation of Students in the Form of University-enterprise Cooperation}

The results of the questionnaires show that among the students surveyed, $11.58 \%$ of the students have participated in the training camps jointly established by companies and universities, $16.84 \%$ in the class of corporate executives, $5.26 \%$ in the entrepreneurial competition, $2.63 \%$ in the entrepreneurship projects or entrepreneurial practices of enterprise. However, it is worth noting that $75.62 \%$ (431 individuals) of the students have never participated in any of the above-mentioned forms of university-enterprise cooperation, which shows that the core problem of current students' entrepreneurial activities is insufficient participation degree of students, and hence more publicity is needed.

\subsection{Students' Evaluation of the Form of University-enterprise Cooperation}

Students who have participated in the above-mentioned university-enterprise cooperation model are generally satisfied with the existing cooperation model. Among all the students who have participated in university-enterprise cooperation, $14.39 \%$ of the students are "very satisfied", $45.32 \%$ "satisfied", $38.13 \%$ "generally satisfied", $1.44 \%$ dissatisfied, and only $0.72 \%$ "very dissatisfied."

Among the students who have participated in the university -enterprise cooperation form, $76.26 \%$ of the students believe that the university-enterprise cooperation form can broaden their horizons, $51.08 \%$ think it can help them improve their ability to use knowledge, $52.52 \%$ think that in the process they can cultivate their business sensitivity, and $33.81 \%$ think it will help them improve their leadership.

In terms of innovation and entrepreneurship education, $54.68 \%$ of the students believe that it can help them enhance their awareness of innovation and entrepreneurship, and $53.96 \%$ believe that they can increase their basic knowledge of entrepreneurship.

The overall satisfaction is encouraging. The abovementioned satisfaction survey results indicate that university-enterprise club activities have benefited students a lot. However, the students who did not participate in the activities of university-enterprise cooperation have zero satisfaction with the above problems.

\subsection{Analysis of The Dissatisfaction with the Situation of University-enterprise Cooperation}

However, there are still some shortcomings. According to the survey results, $66.91 \%$ of the students believe that there are fewer ways to participate in university-enterprise cooperation models, and $61.87 \%$ believe that universities and companies have insufficient publicity for these cooperation methods. At the same time, $56.12 \%$ of the students think that they lack more detailed professional guidance from their universities and the enterprises during the participation process, and $38.85 \%$ believe that the content form of university-enterprise cooperation is single or not abundant enough. The above data shows that there are still many shortcomings in the current activities of university-enterprise cooperation.

\subsection{Students' Expectation on the Form of University-enterprise Cooperation}

In the survey, the project team also collected the expectations of students for the form of universityenterprise cooperation. The survey results show that $73.38 \%$ of the students hope that enterprises participating in the university-enterprise cooperation model can provide students with more opportunities to visit and practice in the enterprise. $71.22 \%$ of the students expect that their universities can provide them more sand-table simulation opportunities, and hence they can be guided by corporate executives. At the same time, $58.99 \%$ of the students hope that companies can provide more support for students' entrepreneurial projects. In addition, $46.04 \%$ of the students suggested that more corporate executives can be admitted to the classroom to teach workplace-related courses.

\section{RESULTS ANALYSIS OF THE SURVEY}

According to the data analysis of the statistical survey, we get the following conclusions.

- Students participating in the university-enterprise cooperation recognize the existing cooperation forms and are highly satisfied with them.

The survey shows that students generally recognize the form of university-enterprise cooperation to provide students with entrepreneurial education, and believe that the model of university-enterprise cooperation can cultivate their multiple abilities. The survey shows that the form of universityenterprise cooperation is very popular among students. It is a beneficial supplement to the undergraduate talent training program, enabling students to learn knowledge other than the school's preset courses, and improve their practical ability and entrepreneurial practice in addition to learning ability. 
- Most students have not participated in the university -enterprise cooperation form so far.

Although there are many forms of universityenterprise cooperation, the survey results show that a large number (more than three-quarters) of students still fail to benefit from this model. Combined with the findings of the students' evaluations, the main problems currently exist: there are few ways for students to participate in the university-enterprise cooperation mode, and hence the promotion of these methods by universities is not strong enough to encourage the participation of most students.

- After participating in the university-enterprise cooperation, students are still lacking in in-depth professional guidance.

The survey shows that more than half of the students believe that they have not received in-depth professional guidance from their universities and the enterprises during the participation process, indicating that under this mode the role of the enterprises and the universities to help students has not been maximized, and the enterprises and the universities have not been fully utilized. The guiding role of the tutors provided by enterprises and universities has not been fully exerted, so that students cannot feel the in-depth guidance from professional tutors.

- There is a lot of room for improvement and development of the existing cooperation models, and there are many opportunities for optimization.

The survey shows that students hope to learn more entrepreneurial experience and knowledge through university-enterprise cooperation. They hope that companies can provide enough opportunities for students to visit companies and let enough senior executives with practical experience join the classroom to pass on their experience. They hope that companies can provide enough funds or intellectual support for the implementation of students' projects in entrepreneurship. In addition, many students hope to take advantage of the cooperation between the university and the company, the university can provide students with sand table teaching (such as simulating real business scenarios, etc.), and they can get enough practical guidance from the related company.

\section{ANALYSIS ON THE COUNTERMEASURES OF UNIVERSITY- ENTERPRISE COOPERATION}

Because students have insufficient understanding of entrepreneurship and are lacking in enough guidance in practice, the current entrepreneurial education benefits students very limite. Based on the analysis conclusions of the survey data, we propose the following countermeasures.
- "Theory + practice" comprehensively enhance the innovation and entrepreneurship consciousness of college students.

Theoretical guidance. First of all, universities should increase investment to cultivate a reliable team of entrepreneurial mentors of "enterprise mentors plus campus mentors". Secondly, universities should reform the existing entrepreneurship curriculum system, and increase practical opportunities in the curriculum, let college students have a deep understanding of the meaning of entrepreneurship, and enhance students' entrepreneurial awareness.

Practical level. Firstly, universities can create an atmosphere encouraging entrepreneurship, such as organizing entrepreneurial competitions related to the majors, undertaking the competitions held by some companies in schools, etc. Secondly, universities can set up a venture fund to provide opportunities for the winning teams and their projects to land in the competition.

The two-pronged approach of "theory + practice" is conducive to comprehensively improving students' entrepreneurial awareness and cultivating their entrepreneurial capabilities.

- Set up a special office to handle universityenterprise cooperation affairs.

In the light of the complicated approval procedures for entering schools and uneven quality of enterprises in the process of school-enterprise cooperation, we recommend that universities set up special offices to integrate existing school-enterprise partnerships, manage administrative approvals for school-enterprise cooperation, and promote schoolenterprise cooperation and entrepreneurship. The smooth development of the activity.

In order to help students fully demonstrate their entrepreneurial ability, it is recommended to establish a long-term cooperative relationship between the university and the enterprise. Enterprises use cooperative channels to carry out entrepreneurial activities needed by enterprises in universities.

- Establish "University-Enterprise Crowdfunding Platform".

According to the survey results, it is difficult for universities to provide sufficient financial support for students' entrepreneurial projects. Therefore, it is recommended to consider the establishment of a "corporate crowdfunding platform."

The university-enterprise cooperation office creates a crowdfunding platform in the name of the university to ensure the credibility and reliability of the crowdfunding platform. The companies participating in the crowdfunding will be selected by the school-enterprise cooperation office. Highquality entrepreneurial projects are selected by the university from the existing entrepreneurial 
competitions. When a student entrepreneurial team has good, feasible, practical, and promising ideas, and meets the screening requirements of relevant standards, it can enter the crowdfunding platform for bidding.

- Make full use of the positive role of the Institute of Innovation and Entrepreneurship Education.

In the current entrepreneurial activities of students, most students lack professional guidance, which makes them prone to making mistakes in the entrepreneurial direction and finally leads to entrepreneurial failures.

In the interview with the entrepreneurial group of students in universities, we find that $81.29 \%$ of students feel that if they don't have enough support, they can't start a business, and $56.12 \%$ feel that there is no competent person to take the lead or no professional mentor guidance. The above data shows that it is necessary to give full play to the window and bridge role of the entrepreneurial education institutes of universities to educate and guide students in innovation and entrepreneurship awareness, entrepreneurship capabilities, and entrepreneurship policies. For example, hold some entrepreneurial experience exchange meetings from time to time, and provide high-quality entrepreneurial teams with policy, capital, land and other resource support and technical support when necessary.

- The school should improve the content of the talent training plan that attracts enterprises to participate in entrepreneurship.

The university needs to strengthen its internal training, create a good entrepreneurial atmosphere in the university, reach a consensus with relevant sponsoring companies of "a consistent goal, mutual penetration, mutual benefit, and common development", and further attract a group of highquality enterprises to join the student entrepreneurship education in the system construction. The mutual assistance system of enterprises, universities, and students will be realized, so as to achieve win-win cooperation.

\section{CONCLUSION}

Based on the existing "innovation and entrepreneurship" atmosphere in China, entrepreneurship education has been paid more and more attention, and the original education model needs to keep pace with the times. This paper focuses on the theme of "how to use the universityenterprise cooperation model to supplement the existing innovation and entrepreneurship teaching", taking 12 universities of Guangdong province as examples to carry out preliminary research.

According to the survey, the existing innovation and entrepreneurship education system in Guangdong Province is relatively complete. However, there are still some problems such as insufficient entrepreneurial awareness of students, insufficient curriculum design, lack of practical opportunities, and insufficient professional guidance. The existing university-enterprise cooperation model is the main entrepreneurial incubation method, including project cooperation system, training camp cooperation model, university-enterprise cooperation competition, and model of enterprise entering school and sharing experience. Students have a high evaluation of the existing model, and they think it is an effective way to learn entrepreneurial knowledge and can improve their entrepreneurial practice ability.

However, the existing model also has many shortcomings. For example, the ways for students to participate in the existing university-enterprise cooperation is very scarce, and it is difficult for the university to meet the students needs. The current university-enterprise cooperation model is not well-known among students, the participation degree of students is less than a quarter, and the quantity and proportion of the participating students are seriously insufficient, etc.

Therefore, this paper proposes to use the universityenterprise cooperation model as an important supplement to the entrepreneurial education talent training program. Through the establishment of a university-enterprise cooperation office, the establishment of a corporate crowdfunding platform managed by the university, the further development of the role of the Institute of Innovation and Entrepreneurship, and the creation of a professional "enterprise mentor plus campus mentor" guidance team, the university-enterprise cooperation model can be fully utilized in entrepreneurship education. And finally we give full play to the effectiveness of the university-enterprise cooperation model in entrepreneurship education, and promote the development and growth of China's entrepreneurship education and entrepreneurial activities.

In China's university, innovation and entrepreneurship education is one of the key issues in the field of students training in China's higher education. How to achieve highquality entrepreneurship education is a important issue. This paper has made preliminary explorations on this issue. Through the investigation, some targeted suggestions were obtained. However, due to time constraints, the research needs to be further deepened, and we will continue to carry out this research in depth in the future.

\section{ACKNOWLEDGMENT}

This paper is funded by the National Natural Science Foundation of China (No. 61877013), the Natural Science Project of Guangdong Province (No. 2018A030313470), Project of Key Laboratory of Language Engineering and Computing of Guangdong Province (No. LEC2020ZBKT002). Teacher \& Student Innovation Project of Guangdong University of Foreign Studies (No.18SS08). 


\section{REFERENCES}

[1] C.J. Qiu, "Research on the Curriculum System of Innovation and Entrepreneurship Education in Chinese Universities," Jiangsu Higher Education [J]. Nanjing, vol. 11, pp. 82-85, November 2018. DOI:10.13236/j. cnki.jshe.2018.11.017. (In Chinese)

[2] Z.X. Huang and L.Y. Guo, "Core Issues about the Construction of Curriculum System of Entrepreneurship Education in University," Exploring Education Development [J]. Shanghai, vol. 32(19), pp. 81-84, October 2012. DOI:10.14121/j.cnki.1008-3855.2012.19. 011. (In Chinese)

[3] W. Gao, "Reflections on and Countermeasures for Deepening the Education of Innovation and Entrepreneurship in Universities," Ideological and theoretical education [J]. Shanghai, vol. 8, pp. 92-95, August 2015. DOI:10.16075/j.cnki.cn31-1220/g4.2015. 08.021. (In Chinese)

[4] X.P. Tian, "Community Construction of Innovation and Entrepreneurship Education from the Perspective of Educational Ecology Theory," Exploring Education Development [J]. Shanghai, vol. 36(7), pp. 66-72, April 2016. DOI:10.14121/j.cnki.1008-3855.2016.07.012. (In Chinese)

[5] J. Chen, "Research on the Construction of University-oriented Entrepreneurship Education Ecosystem," Northeast Normal University [D]. Changchun, pp. 1-117, June 2017. (In Chinese)

[6] X. Cheng and S.Y. Li, "Construction of Measurement Index System and Weight Analysis of University Innovation and Entrepreneurship Education Ecosystem," University Education Science [J]. Changsha, vol. 179, pp. 99-106, January 2020. DOI:10. 3969/j.issn.1672-0717.2020.01.014. (In Chinese)

[7] R.L. Shi and L.M. Zhao, "Collaborative Cultivation Mechanism of Innovative and Entrepreneurial Talents in Higher Vocational Colleges," Education and Vocation [J]. Beijing, vol. 953, pp. 69-72, January 2020. DOI:10. 13615/j.cnki.1004-3985.2020.01.012. (In Chinese)

[8] S.Y. Gao, "Study on Developing Entrepreneurial Skills in the Science \& Engineering Talents," Zhejiang University [D]. Hangzhou, pp. 1-217, October 2013. (In Chinese)

[9] H.J. Wang, "A Study on the Mechanism to Cultivate the Entrepreneurial Competencies for Cross-border E- commerce Talents," Zhejiang University [D]. Hangzhou, pp. 1-199, December 2018. (In Chinese)

[10] M.L. Dong, "Research on the Pattern of the Cooperation and Synergy Development between Stanford University and Silicon Valley Enterprises," Science and Technology Management Research [J]. Guangzhou, vol. 31(18), pp. 64-68, September 2011. DOI:10.3969/j.issn.1000-7695.2011.18.018. (In Chinese)

[11] L.J. Yang, "Research on the Enterprise Education System of Local University Based on CollegeEnterprise Cooperation," Exploring Education Development [J]. Shanghai, vol. 31(5), pp.38-41, March 2011.DOI:10.14121/j.cnki.1008-3855.2011.05.011. (In Chinese)

[12] Y.C. Shen, "Research on the Construction of Entrepreneurship Education Practice Platform for Local Colleges and Universities Based on GovernmentSchool-Enterprise Cooperation," China Higher Education Research [J]. Beijing, vol. 325(9), pp. 37-42, September 2020. DOI:10.16298/j.cnki.1004-3667.2020. 09.08. (In Chinese)

[13] M.X. Xu, C. Li, Y.F. Zhu, and D. Wang, “A Study of University-Industry Collaboration to Promote the e form of Practice Teaching of Innovation and Entrepreneurship," Journal of Changzhou Institute of Technology [J]. Changzhou, vol. 33(3), pp. 75-80, June 2020.DOI:10.3969/j.issn.1671-0436.2020.03.015. (In Chinese)

[14] Y.M. Dong, C.Q. Ye, Y.L. Wang, X. Zhou, and Y. G. Zhu, "University and Enterprise Work Together to Cultivate College Students' Abillity of Innovation and Entrepreneurship Based on the Three-in-one Tutorial System," Higher Education in Chemical Engineering [J]. Shanghai, vol. 37(2), pp. 44-47, April 2020. DOI:10. 3969/j.issn.1000-6168.2020.02.009. (In Chinese)

[15] B.Z. Cheng, Q. Xu, and G.F. Zhang, "Research on Talent Cultivation Mechanism of Industrial Colleges with Deep Integration of Production and Education," Chinese University Science \& Technology [J]. Guangzhou, vol. 35(1), pp. 98-102, February 2021. DOI: 10.16209/j.cnki.cust.2021.z1.021. (In Chinese) 